\title{
Numerical modelling of a steam methane reformer
}

JE Holt $^{1} \quad \mathrm{~J} \mathrm{Kreusser}^{2} \quad$ A Herritsch $^{3} \quad$ M Watson $^{4}$

Received 15 November 2017; revised 1 March 2018

\begin{abstract}
Steam methane reformers are used in industry to convert methane (natural gas) and steam into hydrogen and carbon monoxide. The reformers consist of long pipes filled with catalyst pellets, heated by external burners. Previous researchers have conducted experiments to understand the behaviour of these reformers. Small scale experiments focussed on the reaction kinetics [Xu and Froment, AlChE 35:88-96, 1989). Industrial scale experiments found the effect of diffusional resistance on the reaction rate [Xu and Froment, AlChE 35:97-103, 1989]. From the experiments, a model was created to predict the behaviour of an industrial scale reactor. This model was solved numerically. The model incorporates heat, mass and momentum transfer to describe the temperature, composition and pressure along the reactor. A series of differential equations were solved in order to describe the reformer at
\end{abstract}

Dor:10.21914/anziamj.v59i0.12635, C) Austral. Mathematical Soc. 2018. Published July 5, 2018, as part of the Proceedings of the 13th Biennial Engineering Mathematics and Applications Conference. ISSN 1445-8810. (Print two pages per sheet of paper.) Copies of this article must not be made otherwise available on the internet; instead link directly to the DOI for this article. 
each length segment. Within each segment another series of differential and algebraic equations must be solved to describe the diffusion and reaction behaviour inside the catalyst pores. The numerical model has been replicated in Python. It shows the behaviour of a reformer and the computation time is short enough to be useful in an industrial setting. An open source thermodynamics package was used to calculate various physical properties of the reacting gasses. SciPy mathematical algorithms and functions were used in this replicated model. After finishing the model, it will be regressed against data from a working reformer. Many parameters will be adjusted to ensure the model is an accurate representation.

Subject class: 80A32

Keywords: Numerical modelling; Reforming

\section{Contents}

1 Introduction

C114

2 Model equations

C115

2.1 Reaction Kinetics . . . . . . . . . . . . . . . .

C115

2.2 Diffusional resistance . . . . . . . . . . . . . .

C117

2.3 Temperature . . . . . . . . . . . . . .

2.4 Pressure . . . . . . . . . . . . . . . .

3 Model Structure

C120

4 Results

C122

5 Conclusion

C125

References 


\section{Introduction}

Methanex Corporation, Vancouver, Canada is the world's largest producer of methanol. The largest annual production comes from the three plants in New Zealand who have a combined capacity of $2.4 \times 10^{9} \mathrm{~kg}$ methanol per year. The methanol is manufactured using primarily methane and water as the feedstock. Steam methane reformers are one unit operation of many in this process. Inside these reformers methane, $\mathrm{CH}_{4}$, and water, $\mathrm{H}_{2} \mathrm{O}$, are converted into primarily hydrogen, $\mathrm{H}_{2}$, carbon monoxide, $\mathrm{CO}$, and carbon dioxide, $\mathrm{CO}_{2}$. The three main reactions are:

$$
\begin{gathered}
\mathrm{CH}_{4}+\mathrm{H}_{2} \mathrm{O} \rightarrow \mathrm{CO}+3 \mathrm{H}_{2}, \\
\mathrm{CO}+\mathrm{H}_{2} \mathrm{O} \rightarrow \mathrm{CO}_{2}+\mathrm{H}_{2}, \\
\mathrm{CH}_{4}+2 \mathrm{H}_{2} \mathrm{O} \rightarrow \mathrm{CO}_{2}+4 \mathrm{H}_{2},
\end{gathered}
$$

Reactions 1 and 3 are highly endothermic while reaction 2 is mildly exothermic. Overall the reactions are endothermic so they absorb energy and favour the products at higher temperatures. The reactor therefore needs to be heated to maintain a high temperature for the reaction. As there are more moles of product than reactant, lower pressure favours the products.

The reformers at Methanex's Motunui plant consist of 680 vertical tubes. All tubes are $14 \mathrm{~m}$ long and $110 \mathrm{~mm}$ internal diameter. The tubes are filled with nickel catalysts on an alumina support structure. The mixture of water and methane is fed into the top of the reformer at around $400^{\circ} \mathrm{C}$ and 20 bar gauge. The tubes are arranged in 10 rows of 68 tubes and downwards pointing burners between the rows at the roof of the reformer supply $400 \mathrm{MW}$ of energy for the reactions. The gases exit the bottom of the tubes at around $860^{\circ} \mathrm{C}$ and $17 \mathrm{bar}$ gauge. The outlet temperature has a strong influence on the efficiency of the 
reformer. Higher temperatures result in less unreacted methane leaving the reformer, known as the methane slip. The maximum allowable temperature of the gases is limited, however, by the outlet system material. Above $900^{\circ} \mathrm{C}$ the life of the outlet system material is severely reduced by creep deformation.

The engineers at Methanex would like the ability to model the reformer. A model will be used for diagnosing current issues with the reformer. It can also be used for "what if analysis" such as exploring the use of different catalysts or larger tubes.

Many models have been created to describe reformers with varying levels of detail $[5,6]$. Computational fluid dynamics has been used to describe them with a high accuracy [4]. Many of these take a long time to converge, however, so are impractical for Methanex to use regularly.

In this work a model has been created for the reformer in Python which replicates some of the work of $\mathrm{Xu}$ and Froment $[8,7]$. It is compared with the original model to demonstrate that it a reasonable replica. In future work the model will be regressed against the data supplied by Methanex. Parameters for the reaction kinetics constants, heat flux, pressure drop and catalyst properties will be altered to ensure that the model is an accurate description for the reformers at Methanex, where the model will be used.

\section{Model equations}

The model is based on the work of $\mathrm{Xu}$ and Froment [8, 7]. It is steady state and one dimensional.

\section{$2.1 \quad$ Reaction Kinetics}

Experiments to determine the reaction kinetics were carried out by $\mathrm{Xu}$ and Froment [8] in a small scale reformer. Small catalysts were used to ensure 


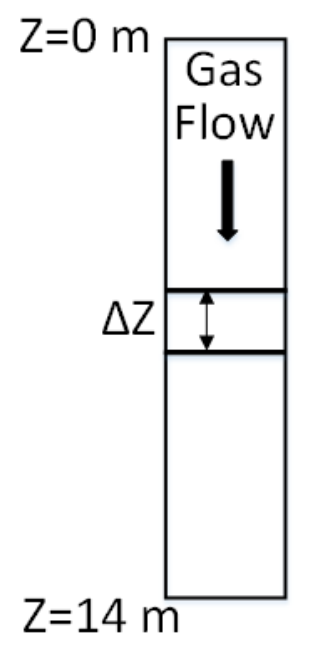

Figure 1: Structure of the tube

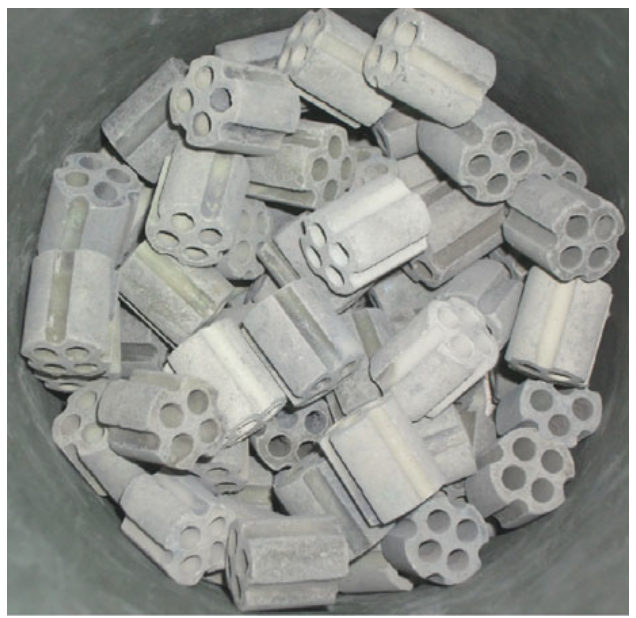

Figure 2: Catalysts used by Methanex photographed in the tube looking from above [9]

that diffusional resistance was not a factor. Six gases were considered in this model, $\mathrm{CH}_{4}, \mathrm{CO}_{2}, \mathrm{CO}, \mathrm{H}_{2}, \mathrm{H}_{2} \mathrm{O}$ and $\mathrm{N}_{2}$.

The rate of change of concentration, $\boldsymbol{c}_{\mathfrak{j}}(z)$, of each of the six gases down the length of the tube, $z$, is described for each gas, $j$, by the equation

$$
\frac{\mathrm{d} c_{j}}{\mathrm{~d} z}=-\frac{1}{v} \frac{1-\varepsilon}{\varepsilon} \rho_{c a t} r_{j} .
$$

The equation is based on a mass balance with advective flow. $v$ is the superficial velocity of the gas in $\mathrm{m} / \mathrm{s}$, defined as the average velocity of the gas in the pipe if there were no catalysts filling it. The superficial velocity is likely to change as the molecular concentration of the gas increases down the tube. $\varepsilon$ is the void fraction of the bed, $\rho_{\text {cat }}$ is the density of the catalyst in $\mathrm{kg} / \mathrm{m}^{3}$ and $\boldsymbol{r}_{j}$ is the rate of disappearance of component $\boldsymbol{j}$ in $\mathrm{kmol} / \mathrm{kg}_{\text {cat }} \mathrm{s}$.

Reaction rates are used to calculate the rate of disappearance of each compo- 
nent. For example:

$$
\mathrm{r}_{\mathrm{CH}_{4}}=\mathrm{r}_{1}+\mathrm{r}_{3},
$$

where $r_{1}$ and $r_{3}$ are the reaction rates of reactions 1 and 3. The reaction rates are calculated using the method outlined in $\mathrm{Xu}$ and Froment [8]. The form of these equations is well established but parameters such as the activity coefficients will be adjusted later. Rates of disappearance will be negative for some of the gases indicating that they are being created.

\subsection{Diffusional resistance}

In industrial reformers the catalysts are much larger than in the small scale experiments performed by $\mathrm{Xu}$ and Froment [8]. The catalysts used by them were rings with diameter of $17 \mathrm{~mm}$. Diffusional resistance is significant at that scale so needs to be accounted for. Catalysts are highly porous and reactions can be catalysed at any point on the surface of these pores. Unfortunately the reactants must diffuse in and the products must diffuse out of the catalyst and back into the bulk gas. For this size of catalyst the effects of diffusion can be significant and the reactions only take place near the outside of the catalyst. $\mathrm{Xu}$ and Froment [7] investigated the effect of diffusion by performing experiments on an industrial sized reformer. Since the partial pressure gradients are only near the surface, the diffusion equations are based on a planar geometry. The partial pressure profiles of $\mathrm{CH}_{4}$ and $\mathrm{CO}_{2}$ inside the catalyst at any particular point down the length of the tube are described by:

$$
\begin{aligned}
& \mathrm{D}_{e, \mathrm{CH}_{4}} \frac{\mathrm{d}^{2} \mathrm{p}_{\mathrm{s}, \mathrm{CH}}}{\mathrm{d} \xi^{2}}=10^{-2} \mathrm{RT} \cdot \mathrm{R}_{\mathrm{p}}^{2} \cdot \mathrm{r}_{\mathrm{CH}_{4}}\left(\mathrm{P}_{\mathrm{s}}\right) \rho_{\mathrm{s}}, \\
& \mathrm{D}_{e, \mathrm{CO}_{2}} \frac{\mathrm{d}^{2} p_{\mathrm{s}, \mathrm{CO}_{2}}}{\mathrm{~d} \xi^{2}}=10^{-2} \mathrm{RT} \cdot \mathrm{R}_{\mathrm{p}}^{2} \cdot \mathrm{r}_{\mathrm{CO}_{2}}\left(\mathrm{P}_{\mathrm{s}}\right) \rho_{\mathrm{s}},
\end{aligned}
$$


where $\mathrm{D}_{e, \mathrm{CH}_{4}}$ is the effective diffusivity of $\mathrm{CH}_{4}, \mathrm{p}_{\mathrm{s}, \mathrm{CH}_{4}}$ is the partial pressure of $\mathrm{CH}_{4}$ inside the catalyst, $\mathrm{R}_{\mathrm{p}}$ is the effective radius of the catalyst and $\mathrm{r}_{\mathrm{CH}_{4}}\left(\mathrm{P}_{\mathrm{s}}\right)$ is the rate of disappearance of $\mathrm{CH}_{4}$ at that point in the catalyst, calculated using the partial pressures, $p_{j}$ of all components contained in vector $P_{s}$. $\xi$ is the dimensionless diffusional path length where $\xi=0$ at the centre of the catalyst and $\xi=1$ at the surface.

The other 3 components, $\mathrm{CO}, \mathrm{H}_{2} \mathrm{O}$ and $\mathrm{H}_{2}$ are described by algebraic equations which are derived from atomic balances for the 3 reactions.

$$
\begin{gathered}
p_{s, \mathrm{CO}}=\frac{D_{e, \mathrm{CO}_{2}}}{D_{e, \mathrm{CO}}}\left(p_{\mathrm{CO}_{2}}-p_{s, \mathrm{CO}_{2}}\right)-\frac{D_{e, \mathrm{CH}_{4}}}{D_{e, \mathrm{CO}}}\left(p_{s, \mathrm{CH}_{4}}-p_{\mathrm{CH}_{4}}\right)+p_{\mathrm{CO}} \\
p_{s, \mathrm{H}_{2} \mathrm{O}}=\frac{D_{e, \mathrm{CO}_{2}}}{D_{e, \mathrm{H}_{2} \mathrm{O}}}\left(p_{\mathrm{CO}_{2}}-p_{s, \mathrm{CO}_{2}}\right)+\frac{D_{e, \mathrm{CH}_{4}}}{D_{e, \mathrm{H}_{2} \mathrm{O}}}\left(p_{s, \mathrm{CH}_{4}}-p_{\mathrm{CH}_{4}}\right)+p_{\mathrm{H}_{2} \mathrm{O}} \\
p_{\mathrm{s}, \mathrm{H}_{2}}=\frac{D_{e, \mathrm{CO}_{2}}}{D_{e, \mathrm{H}_{2}}}\left(p_{s, \mathrm{CO}_{2}}-p_{\mathrm{CO}_{2}}\right)-\frac{3 D_{e, \mathrm{CH}_{4}}}{D_{e, \mathrm{H}_{2}}}\left(p_{s, \mathrm{CH}_{4}}-p_{\mathrm{CH}_{4}}\right)+p_{\mathrm{H}_{2}} .
\end{gathered}
$$

At the outside surface of the catalyst the composition of the gases will be the same as in the bulk gas and in the middle of the catalyst there will be no composition gradient as the catalyst profile will be symmetrical. These boundary conditions are expressed as:

$$
\begin{gathered}
\frac{d p_{\mathrm{s}, \mathrm{CH}_{4}}}{\mathrm{~d} \xi}=\frac{\mathrm{d} p_{\mathrm{s}, \mathrm{CO}_{2}}}{\mathrm{~d} \xi}=0 \text { at } \xi=0, \\
\mathrm{p}_{\mathrm{s}, \mathrm{CH}_{4}}=\mathrm{p}_{\mathrm{CH}_{4}} \text { and } \mathrm{p}_{\mathrm{s}, \mathrm{CO}_{2}}=\mathrm{p}_{\mathrm{CO}_{2}} \text { at } \xi=1 .
\end{gathered}
$$


Solving these equations produces a concentration profile inside the catalysts. The reaction rate used in the equation 4 is calculated as the volume averaged reaction rate in the catalyst.

Diffusion coefficients are dependent on both molecular and Knudsen diffusivities $D_{k j}$. Effective diffusivity is adjusted to account for the nature of the catalyst pores using the porosity and tortuosity of the catalyst [1]. Details of the method are outlined in $\mathrm{Xu}$ and Froment [7]. Parameters such as the tortuosity and porosity will be changed to suit the catalyst during regression.

\subsection{Temperature}

Two contributions to the temperature, $\mathrm{T}(\boldsymbol{z})$ of the tube were considered: the heat flux from the external burners and the heat produced or consumed by the reactions. These are added together in Equation 13.

$$
\frac{\mathrm{dT}}{\mathrm{d} z}=\frac{1}{\mathrm{c}_{\mathrm{p}} \rho_{\mathrm{g}} v}\left[\rho_{\mathrm{b}}\left(-\Delta \mathrm{H}_{1} \mathrm{r}_{1}-\Delta \mathrm{H}_{2} \mathrm{r}_{2}-\Delta \mathrm{H}_{3} \mathrm{r}_{3}\right)-4 \frac{\mathrm{U}}{\mathrm{d}_{\mathrm{in}}}\left(\mathrm{T}-\mathrm{T}_{\mathrm{r}}\right)\right],
$$

where $c_{p}$ is the specific heat of the gas, $\rho_{g}$ is the density of the gas, $\rho_{b}$ is the density of catalyst in the bed $\left(\mathrm{kg}_{\text {cat }} / \mathrm{m}^{3}{ }_{\mathrm{r}}\right), \Delta \mathrm{H}_{\mathrm{i}}$ is the enthalpy of reaction $i, d_{i n}$ is the internal diameter of the tube, $U$ is the overall heat transfer coefficient of the tube and catalyst bed $\left(\mathrm{W} / \mathrm{m}^{2} \mathrm{~K}\right)$ and $\mathrm{T}_{\mathrm{r}}$ is the outside wall temperature. The model for the overall heat transfer coefficient provided by $\mathrm{Xu}$ and Froment [7] did not give reasonable results. The Leva model from Froment, Bischoff, and De Wilde [1] was used instead. Parameters involved in calculating the overall heat transfer coefficient are likely to change during regression. 


\subsection{Pressure}

The pressure drop model was also obtained from Froment, Bischoff, and De Wilde [1]. The pressure change, $d p_{t} / d z$, is due to the friction in the pipes and is described by the equation:

$$
-\frac{d p_{t}}{d z}=\frac{f \rho_{g} v^{2}}{d_{p}},
$$

where $p_{t}(z)$ is the total pressure of the gas, $d_{p}$ is the diameter of the catalyst pellets and $v$ is the superficial velocity of the gas.

The friction factor, $f$, is calculated using the Hicks equation [3] and fits both low and high Reynolds number data very well. Many of the parameters in the Hicks equation will be changed during regression as they are very dependent on the catalyst shape.

\section{Model Structure}

The model described above was implemented in Python, making use of computing power not available to $\mathrm{Xu}$ and Froment [8, 7]. An Excel interface is used to make the model accessible for engineers with little Python knowledge. Here parameters such as the initial conditions and catalyst properties can be inputted and interpreted by the Python code. SciPy mathematical algorithms were used to solve equations in the model. These were scipy.integrate.odeint, scipy.integrate.solve_bvp and scipy.optimize.fsolve.

The open source thermodynamics package Cantera [2] is used to calculate various physical properties of the gases, most notably the diffusivity of the gases at each point in the catalyst. The equilibrate function of Cantera is used to find the equilibrium concentrations for all conditions encountered in the tube and catalysts. 
The function odeint solves a system of ordinary differential equations and was used for integrating down the length of the tube. It is supplied with initial conditions for the tube and other parameters. It solves the 8 differential equations describing the six gas compositions (Equation 4), temperature (Equation 13) and pressure (Equation 14). Many intermediate variables must be calculated before the differential equations. While most of these variables, such as friction factor, are calculated by simple algebraic equations, the reaction rates are more difficult.

The function solve_bvp was used to solve equations 6 and 7 . It was chosen over odeint because the equations are bounded at both ends. It receives an initial mesh of positions inside the catalyst and an initial guess for partial pressures at each mesh point. In order to integrate these diffusion equations, the second order differential equations are reduced to two first order differential equations using dummy variables, $\mathrm{u}_{1}$ and $\mathrm{u}_{2}$. For example for methane:

$$
\begin{gathered}
\frac{d p_{s, C H_{4}}}{d \xi}=u_{1}, \\
\frac{d u_{1}}{d \xi}=\frac{10^{-2} R T R_{p}^{2} r_{C H_{4}}\left(P_{s}\right) \rho_{s}}{D_{e, C_{4}}} .
\end{gathered}
$$

This set of 4 differential equations is used by solve_bvp to calculate the partial pressure profile inside the catalyst. An accurate initial guess is extremely important for solve_bvp to converge quickly. For the first run (at the top of the tube) the initial guess for $p_{s, C_{4}}$ and $p_{s, \mathrm{CO}_{2}}$ is a second order polynomial profile bounded by the centre and outside of the catalyst. The outside is the partial pressure in the bulk gas as specified by the boundary conditions of the differential equations. The inside is calculated as the equilibrium partial pressure as specified by Cantera. While this is not the condition in the middle of the catalyst, it is closer to the actual inside of the catalyst than the outside partial pressure. After this initial iteration, the previous profile is used as the 
initial guess at every step down the tube. This guess is generally a very good approximation of the actual profile so allows solve_bvp to converge quickly.

At each point in the catalyst, fsolve is used to calculate the partial pressures of $\mathrm{H}_{2}, \mathrm{H}_{2} \mathrm{O}$, and $\mathrm{CO}$ using (Equations 8, 9 and 10). The first iteration is at the edge of the catalyst where the partial pressure of the 3 components is simply the pressure of the bulk gas as specified by odeint. At each subsequent step the initial guess for the partial pressures is the condition at the previous step. This is generally a good approximation as the partial pressure profiles will be smooth in the catalyst.

\section{Results}

The diffusion model was run with the conditions used by $\mathrm{Xu}$ and Froment [7] $4 \mathrm{~m}$ down the tube. Figure 3 compares the partial pressures profile found by the python model compared with the one found by Xu and Froment [7]. The profiles are all very similar in shape. Any differences may be due to the diffusivities used. Calculating the effective diffusivity involves many parameters and not all the ones used by $\mathrm{Xu}$ and Froment [7] are known. Cantera was used for the calculation of the molecular diffusivities for this model while $\mathrm{Xu}$ and Froment [7] did not specify how the molecular diffusivities were calculated.

The model for the whole tube was run with the same conditions as the industrial reformer used by $\mathrm{Xu}$ and Froment [7]. Several key variables were tracked for comparison. Figures 4 and 5 show that the two models match up well in general behaviour showing that the Python model is adequate at describing the reformer. The Python pressure drop was not as large as the one found by $\mathrm{Xu}$ and Froment [7] and the temperature increase and methane conversion were larger. The differences between the Python model and the Xu and Froment [7] model could have been caused by inaccuracies in estimating the void fraction of the bed. The carbon dioxide conversions match very well. 


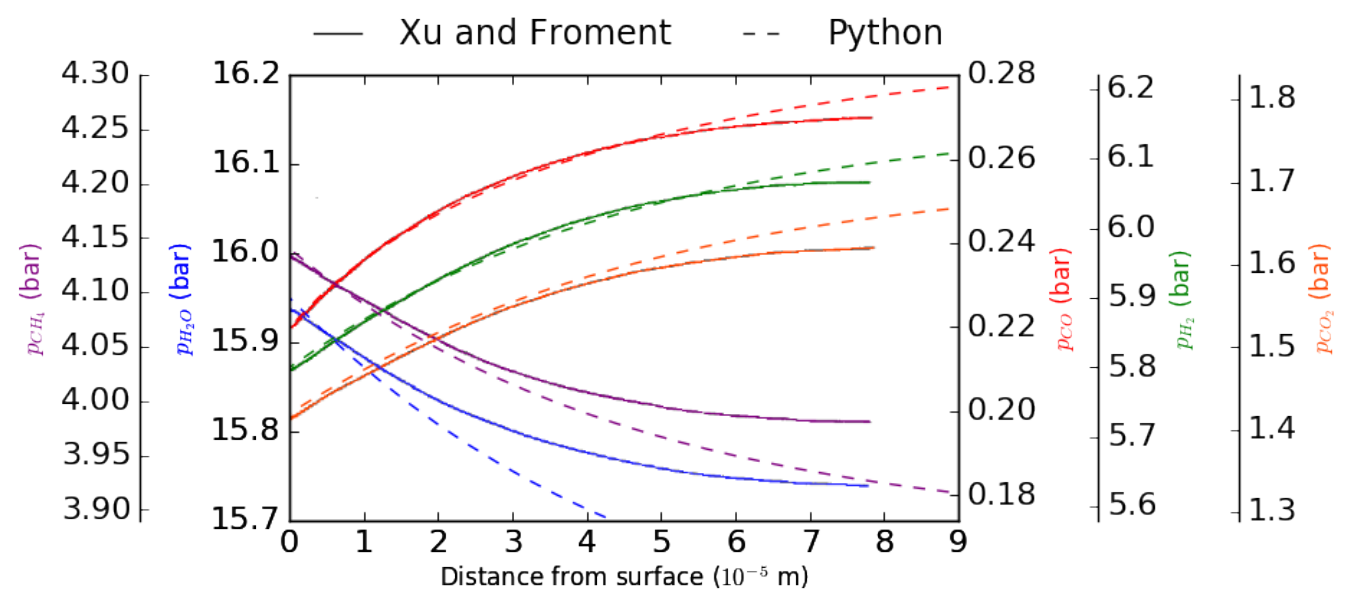

Figure 3: The partial pressure profile in the outer $9 \times 10^{-5} \mathrm{~m}$ of catalyst at $z=4.0 \mathrm{~m}$ compared with the $\mathrm{Xu}$ and Froment [7] model.

The reaction rates do not match as closely, however, the model describes the general pattern of behaviour very well. The reaction rate 2 reverses direction between three and four metres down the tube as the temperature increases and the equilibrium point shifts.

An energy balance was performed to verify the model by calculating the amount of energy passing in and out of each segment of tube as shown in Equation 17.

$$
\frac{\mathrm{dE}_{\mathrm{k}}}{\mathrm{dt}}=\mathrm{h}_{\mathrm{k}-1} \dot{\mathrm{m}}-\mathrm{h}_{\mathrm{k}} \dot{\mathrm{m}}-4 \frac{\mathrm{U}_{\mathrm{k}}}{\mathrm{d}_{\mathrm{in}}}\left(\mathrm{T}_{\mathrm{k}}-\mathrm{T}_{\mathrm{r}, \mathrm{k}}\right) \mathrm{V}_{\mathrm{k}},
$$

where $\frac{d E_{k}}{d t}$ is the net change in energy in segment $k, h_{k}$ is the enthalpy of the gases at point $k$ in the tube, $\dot{m}$ is the mass flow rate of the gas and $V_{k}$ is the volume in the tube between points $k-1$ and $k$. The sources of energy included the enthalpy of gases entering and leaving and the heat flux through the tube wall. As the system is at steady state the energy flow in 


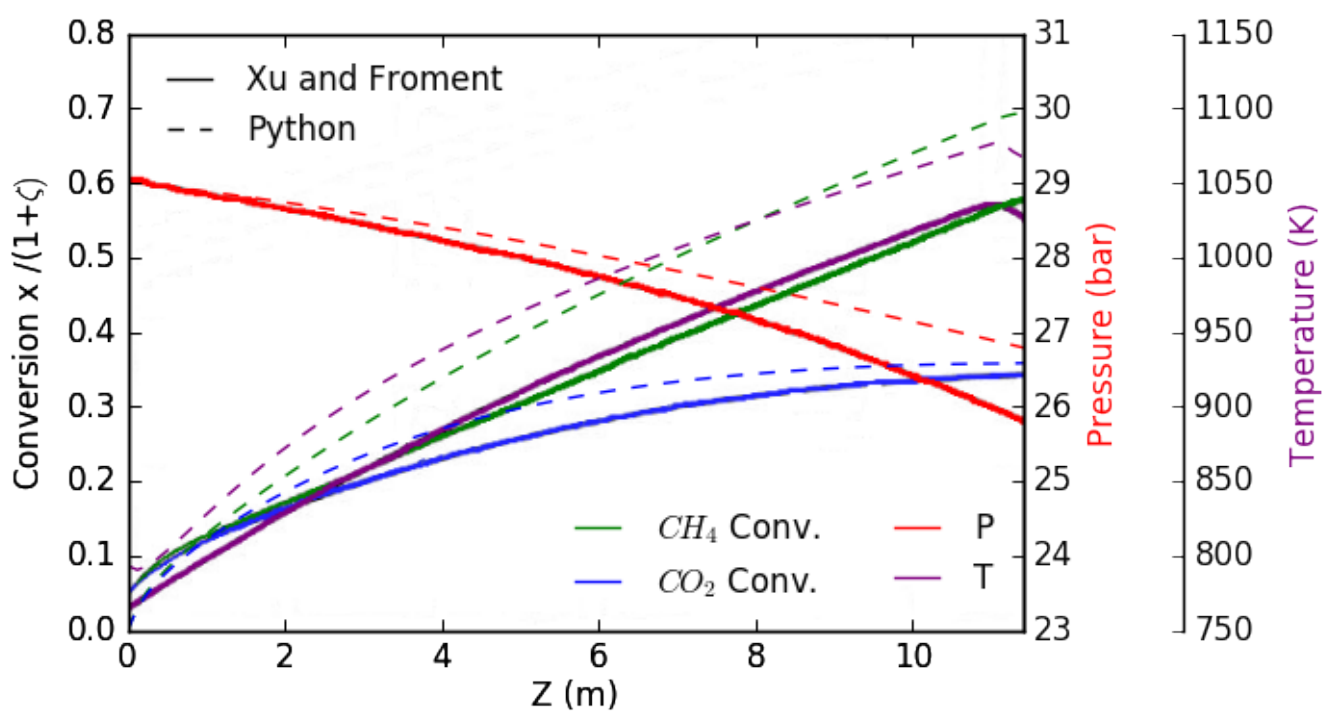

Figure 4: The pressure, temperature, $\mathrm{CO}_{2}$ and $\mathrm{CH}_{4}$ conversions are compared with those found by $\mathrm{Xu}$ and Froment [7] in their model.

should be equal to the energy out for every segment in the tube. In every segment the the net energy flow $\left(\frac{\mathrm{dE}_{\mathrm{k}}}{\mathrm{dt}}\right)$ is less than $0.2 \%$ of the energy in or out. This difference is smaller than the accuracy of the numerical methods so is acceptable.

The Python model is a close enough approximation model results provided by $\mathrm{Xu}$ and Froment [7]. The next step is to compare the model with Methanex data where the regression will be thorough to ensure the model accurately represents the real reformers at Methanex. Other elements will be added such as interactions with the flue gas surrounding the tubes and transient behaviour. Finally the Excel interface will be improved so it is user friendly. 


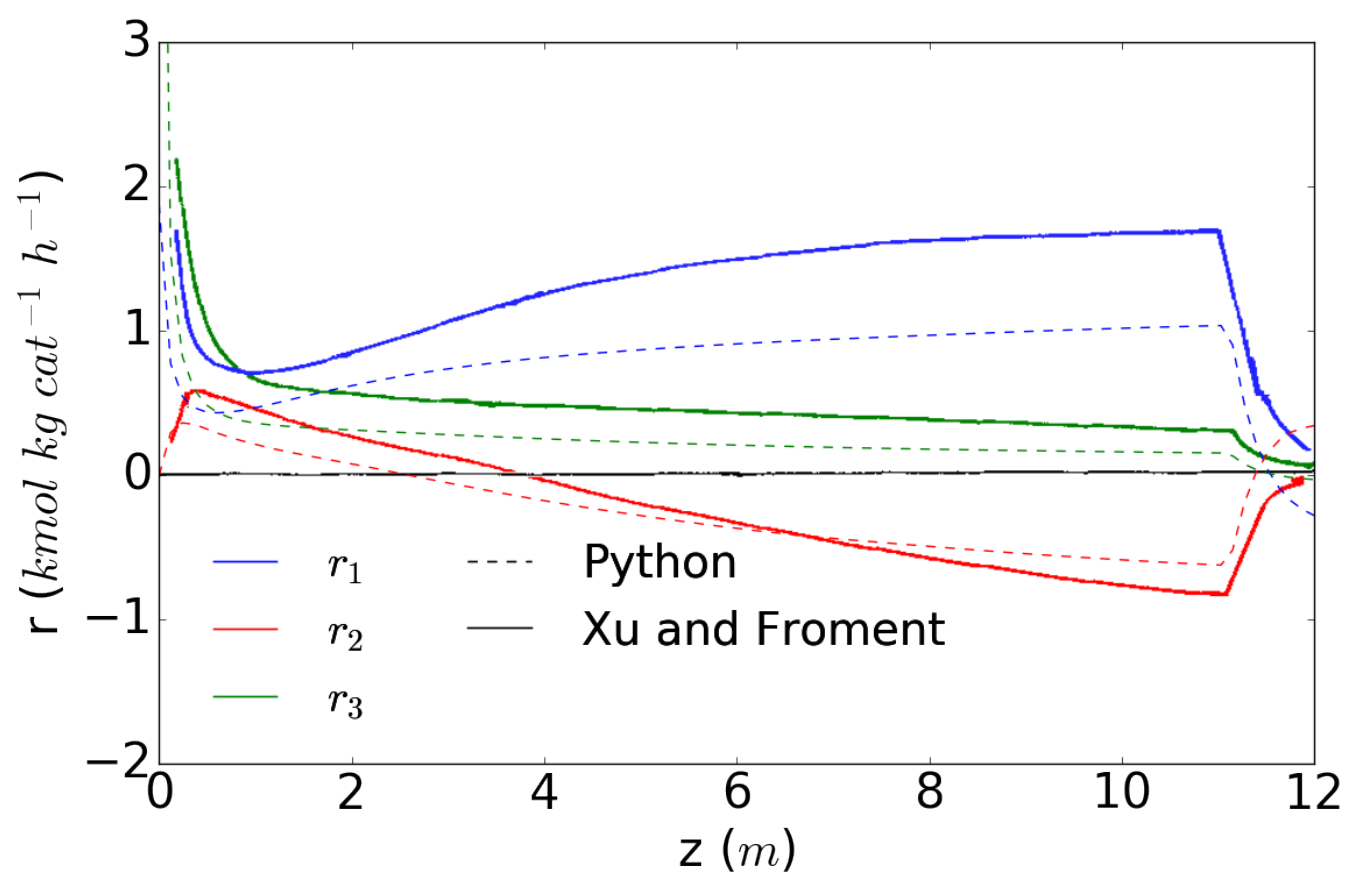

Figure 5: The intrinsic reaction rates in the reformer. The Python model is compared with Xu and Froment [7].

\section{Conclusion}

A model for a steam methane reformer has been replicated in Python. A series of differential equations describe the reaction kinetics, temperature and pressure changes down the tube. A second system of differential equations describes the diffusional resistance in the catalyst at any point in the tube. The Python model has been compared with the original model it was based on. The model is shown to be a reasonable replica of the original. Future work will regress the model against the reformers currently running at Methanex. 


\section{References}

[1] G.F. Froment, K.B. Bischoff, and J. De Wilde. Chemical Reactor Analysis and Design, 3rd Edition. John Wiley \& Sons, Incorporated, 2010. URL: https://books .google.co.nz/books?id=lbQbAAAAQBAJ. C119, C120

[2] David G. Goodwin, Harry K. Moffat, and Raymond L. Speth. Cantera: An object-oriented software toolkit for chemical kinetics, thermodynamics, and transport processes. http://www. cantera.org, 2017. Version 2.3.0. C120

[3] R. E. Hicks. Pressure drop in packed beds of spheres. Industrial $\&$ Engineering Chemistry Fundamentals, 9(3):500-502, 1970. doi:10.1021/i160035a032. C120

[4] Liangfeng Lao, Andres Aguirre, Anh Tran, Zhe Wu, Helen Durand, and Panagiotis D. Christofides. Cfd modeling and control of a steam methane reforming reactor. Chemical Engineering Science, 148:78 - 92, 2016. doi:10.1016/j.ces.2016.03.038. C115

[5] Dean A. Latham, Kimberley B. McAuley, Brant A. Peppley, and Troy M. Raybold. Mathematical modeling of an industrial steam-methane reformer for on-line deployment. Fuel Processing Technology, 92(8):1574 - 1586, 2011. doi:10.1016/j.fuproc.2011.04.001. C115

[6] Jae Seong Lee, Juhyeong Seo, Ho Young Kim, Jin Taek Chung, and Sam S. Yoon. Effects of combustion parameters on reforming performance of a steamâĂŞmethane reformer. Fuel, 111:461 - 471, 2013. doi:0.1016/j.fuel.2013.04.078. C115

[7] Jianguo Xu and Gilbert F. Froment. Methane steam reforming: Ii. diffusional limitations and reactor simulation. AIChE Journal, 35(1):97-103, 1989. doi:10.1002/aic.690350110. C115, C117, C119, C120, C122, C123, C124, C125 
[8] Jianguo Xu and Gilbert F. Froment. Methane steam reforming, methanation and water-gas shift: I. intrinsic kinetics. AIChE Journal, 35(1):88-96, 1989. doi:10.1002/aic.690350109. C115, C117, C120

[9] Alice Young, Sam Henderson, Liam Buchanan, Daniel Hall, and Catherine Bishop. Failure of commercial extruded catalysts in simple compression and bulk thermal cycling. International Journal of Applied Ceramic Technology, 15(1):74-88, 2018. doi:10.1111/ijac.12788. C116

\section{Author addresses}

1. JE Holt, Department of Chemical and Process Engineering, University of Canterbury, New Zealand

2. J Kreusser, Laboratory of Engineering Thermodynamics, University of Kaiserslautern, Germany

3. A Herritsch, Department of Chemical and Process Engineering, University of Canterbury, New Zealand

4. M Watson, Department of Chemical and Process Engineering, University of Canterbury, New Zealand mailto:mat thew. watson@canterbury.ac.nz 